HEDL-7533

\title{
APPLICATION OF HIGH FLUENCE FAST REACTOR DATA TO FUSION-RELEVANT MATERIALS PROBLEMS
}




\section{DISCLAIMER}

Portions of this document may be illegible in electronic image products. Images are produced from the best available original document. 


\title{
APPLICATION OF HIGH FLUENCE FAST REACTOR DATA TO FUSION-RELEVANT MATERIALS PROBLEMS
}

\author{
F.A. Garner \\ Manuscript Completed: April 1985 \\ Date Published: May 1985
}

\section{DISCLAIMER}

\begin{abstract}
This report was prepared as an account of work sponsored by an agency of the United States Government. Neither the United States Government nor any agency thereof, nor any of their employees, makes any warranty, express or implied, or assumes any legal liability or responsibility for the accuracy, completeness, or usefulness of any information, apparatus, product, or process disclosed, or represents that its use would not infringe privately owned rights. Reference herein to any specific commercial product, process, or service by trade name, trademark, manufacturer, or otherwise does not necessarily constitute or imply its endorsement, recommendation, or favoring by the United States Government or any agency thereof. The views and opinions of authors expressed herein do not necessarily state or reflect those of the United States Government or any agency thereof.
\end{abstract}


APPLICATION OF HIGH FLUENCE FAST REACTOR DATA TO FUSION-RELEVANT MATERIALS PROBLEMS

F. A. Garner (Hanford Engineering Development Laboratory)

$1.0 \quad$ Objective

The object of this effort is reassess the utility of fast reactors to fusion materials studies in light of recent insights on the response of materials to radiation exposure at different levels of helium.

\section{$2.0 \quad$ Summary}

In three recent comparative studies in HFIR and EBR-II where the effect of helium and solid transmutants could be assessed, it was found that in each case there was no significant perturbation of the macroscopic property change under consideration. These findings reinforce the belief that fast reactors can serve as a major tool for fusion materials studies and that the effects of helium and other transmutants can be treated as second-order perturbations to be studied by other methods. A number of new fusion-relevant insights derived from fast reactor studies are presented.

\subsection{Program}

Title: Irradiation Effects Analysis (AKJ)

Principal Investigator: D. G. Doran

Affiliation: Hanford Engineering Development Laboratory

\subsection{Relevant DAFS Program Plan Task/Subtask}

Subtask II.C.I Effects of Material Parameters on Microstructure

Subtask II.C.2 Effects of He on Microstructure

Subtask II.C.7 Effects of He and Displacement on Flow

Subtask II.C.8 Effects of He and Displacement on Fracture

\subsection{Accomplishments and Status}

\subsection{Introduction}

The design of fusion devices requires the capability to predict radiation-induced changes in the properties and dimensions of structural materials. In the absence of a test device with a fusion-typical neutron spectrum this objective necessitates three types of activities. First, a sufficiently large data base at high neutron fluence must be derived from existing fission reactors for each property of interest. Second, a correct perception must be attained of the operating damage mechanisms and their response in the fission reactor to material and environmental variables. Finally, one must identify the consequences of differences in neutron spectra and operational variables between anticipated fusion environments and the fission environment from which the data were derived. Currently, we can only assume that the use of displacements per atom adequately describes the damaging characteristics of neutrons at fusion-relevant energies and only limited data are available concerning the potential impact of spectrum-dependent transmutants. $(1)$ 
Until a high flux fusion neutron facility is available, the U.S. materials community is using a variety of neutron sources to conduct experimental studies. The nature of the differences between fission and fusion neutrons is being studied in comparative low flux irradiations in RTNS-II and low power thermal reactors. (1) Although we anticipate the eventual use of the FMIT facility at high displacement rates, we must at this time rely on fast reactors and high flux mixed-spectrum reactors. While the latter have very high qamma heating rates and space limitations, they have been quite useful in investigating the impact of large amounts of helium on damage evolution in alloys that contain nickel.

The question of helium's influence in altering the response of materials to displacive irradiation is the subject of intensive world-wide investigation, but in three cases where a clear comparison can be made at both high and low helium levels, it was found that large levels of helium did not significantly perturb the macroscopic property change under consideration. It was found that the post-transient swelling rate of annealed AISI 316 stainless steel was not altered by the large differences in helium/dpa ratio obtained in EBR-II and HFIR; nor was it influenced by the much higher cavity density generated in HFIR(2,3). It was later determined that the tensile properties of $20 \%$ cold-worked AISI 316 stainless steel irradiated below $575^{\circ} \mathrm{C}$ were also insensitive to the large difference in helium generation rates in these two reactors. (4) Finally, the ductility loss exhibited by high nickel precipitation-hardened austenitic a lloys in HFIR (5) was identical to that observed in EBR-II. 6,7$)$ Thus, the response of these alloys to displacement damage and environmental variables overwhelmed the effect of large amounts of helium. These findings reinforce our decision to use fast reactors as a major tool for fusion materials studies and to treat helium effects as a second-order perturbation to be studied separately.

It is recognized, however, that this approach may not be valid for all alloys and all property changes of interest. Therefore studies are being continued in mixed spectrum reactors. Another approach is also being employed which concentrates on fast reactor irradiations and which introduces helium prior to or during irradiation.

The first of these techniques involves the use of the "tritium trick" to introduce helium into a portion of the specimen matrix prior to irradiation. (8) This technique is valuable for materials such as vanadium alloys that do not contain nickel and therefore will not produce sianificant amounts of helium in mixed spectrum reactors. The second approach involves the reirradiation in FFTF of a series of specimens previously irradiated in HFIR to different displacement levels and helium levels. ( 9 ) The most unique approach involves enrichment of the $59 \mathrm{Ni}$ isotope prior to irradiation in FFTF. (10) This approach al lows helium to be generated during fast-reactor irradiation at fusion-relevant rates. Approximately 50 grams of nickel enriched to $22 \%$ in $59 \mathrm{Ni}$ have been extracted from Inconel 600 which was irradiated to a high fluence in ETR. Experiments utilizing this material are now being planned to study the synergistic effect of helium on void, dislocation, precipitate and spinodal evolution.

The EBR-II fast reactor was previously the major U.S. source of fusion-relevant data in the range of $400-700^{\circ} \mathrm{C}$ and reached exposures as large as $100 \mathrm{dpa}$ in some experiments. EBR-II has now been supplanted by FFTF as the major irradiation facility. It has a much larger experimental volume, a higher displacement rate and on-line temperature control to $+5^{\circ} \mathrm{C}$. On-line stress rupture detection using isotopic tagging of fill gases is also a feature of current FFTF fusion-related studies (11). The materials open test assembly (MOTA) in FFTF is the major experimental vehicle and is currentiy discharging specimens at increments of $230 \mathrm{dpa}$ each year.

\subsection{New Insights Derived from Fast Reactor Irradiations}

Since the validity of any fission-fusion correlation is strongly dependent on the soundness of the property-change description in the fission environment, an increased emphasis has been placed on examination of previously developed correlations for swelling, creep, mechanical properties and phase stability. This attention has led to important revisions in some of our perceptions of the various damage processes, their relative importance and their dependence on material and environmental parameters. One unanticipated major conclusion is that differences in environmental variables such as temperature history and displacement rate are at least as important as differences arising from neutron spectral considerations $(2)$.

Perhaps the most far-reaching revision involves the realization that the steady-state or post-transient swelling rate of all austenitic alloys $j \mathrm{~s} \omega \% / \mathrm{dpa}$, essentially independent of composition, temperature, displacement rate, stress and helium. 72 ) This conclusion has led to a reduction of effort on austenitic PCA alloys and an enhanced interest in ferritic alloys. In the recent Blanket Comparison and Selection Study for instance, austenitic alloys were not recommended for high exposure applications. (12) This conclusion has also led to reassessments in the theoretical descriptions employed to describe swelling(13,14) and in the correlation of results between neutron and charged particle irradiation. $(15,16)$ 
0 ther recent conclusions for austenitic steels were that the primary influcence of all variables lay in the duration of the transient regime of swelling, that swelling did not saturate at engineering-relevant levels and that the sensitivities of the swelling transient regime would be reflected in the sensitivities of transient creep but not in the post-transient creep rate. (7)

Since these findings were published additional data have been acquired which confirm their validity. Exposures of simple $\mathrm{Fe}-\mathrm{Cr}-\mathrm{Ni}$ ternary alloys have now reached $110 \mathrm{dpa}$ in EBR-II. It was found that $1 \% / \mathrm{dpa}$ is eventually reached at all compositions in the range $12-75 \%$ nickel and $7-22 \%$ chromium. (13) Simple $\mathrm{Fe}-\mathrm{Cr}-\mathrm{Mn}$ ternaries and solute-modified $\mathrm{Fe}-\mathrm{Cr}-\mathrm{Mn}-\mathrm{Ni}$ alloys also appear to reach $1 \% / \mathrm{dpa} .(14,15)$ As shown in Figures 1 and 2, structural alloys such as OKh16N15M3B and AISI 316 have also been reported to develop temperature- independent swelling rates of $1 \% / \mathrm{dpa} .(16,17)$ The addition of titanium, phosphorus and other solutes to AISI 316 have been shown to delay but not to preclude the inevitability of reaching this swelling rate. $(18,19)$

In $\mathrm{Fe}-\mathrm{Cr}-\mathrm{Ni}$ and possibly in the $\mathrm{Fe}-\mathrm{Cr}-\mathrm{Mn}$ systems there appears to be a minimum transient regime of ulo dpa that cannot be reduced by application of stress, off-normal temperature histories or variations in displacement rate. $(13,18)$ The swelling of ternary alloys is independent of temperature from the lowest test temperature $\left(400^{\circ} \mathrm{C}\right)$ to some composition-dependent upper limit as shown in Figure 3 . Above this temperature the transient duration increases with temperature. In general the transient regime increases with decreasing chromium (Figure 4) and increasing nickel (Figure 5). At relatively high temperatures, however, swelling again increases with increasing nickel as shown in Figures 5 and 6 .

The compositional dependence of swelling arises from the strong effect of nickel content on two competing processes. The first is the effect of solvent composition on the effective vacancy diffusion coefficient and thereby on void nucleation. The second is the tendency of $\mathrm{Fe}-\mathrm{Ni}-\mathrm{Cr}$ alloys to undergo spinodal decomposition during either neutron or ion irradiation $(19,20)$ as shown in Figure 7 . In $\mathrm{Fe}-35 \mathrm{Ni}-7 \mathrm{Cr}$ the alloy decomposes toward $\mathrm{Fe}_{3} \mathrm{Ni}$ and $\mathrm{FeNi}$. Both of these processes increase with irradiation temperature. Nickel enhances vacancy diffusion and increases the tendency toward decomposition. Chromium on the other hand decreases vacancy diffusion and appears to be relatively inert in spinodal formation. The microoscillations in composition produce large areas which favor void nucleation since they are relatively low in nickel and high in chromium. Associated with the spinodal formation are a decrease in lattice parameter, a loss of the anomalous properties characteristic of the Invar compositional regime and a significant increase in yield strength. $(21)$

\section{$5.3 \quad$ Consequences of Swelling}

It is sometimes proposed that some fusion components can be relatively tolerant of swelling. There are newly discovered consequences, however, that mitigate against such a philosophy. First of all, there will be significant changes in thermal conductivity and elastic moduli. (22) Second, it appears that at swelling levels on the order of 5-10\% there are significant changes in both irradiation creep and fail-

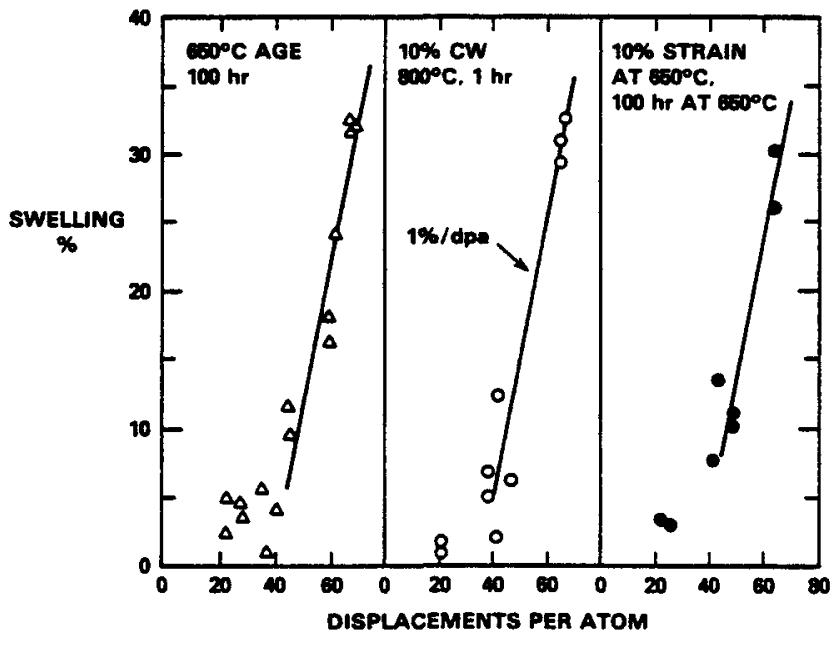

FIGURE 1. Swelling of OKh 16 N15M3B steel in BOR-60 Fast Reactor at $400-550^{\circ} \mathrm{C} .(19)$ 


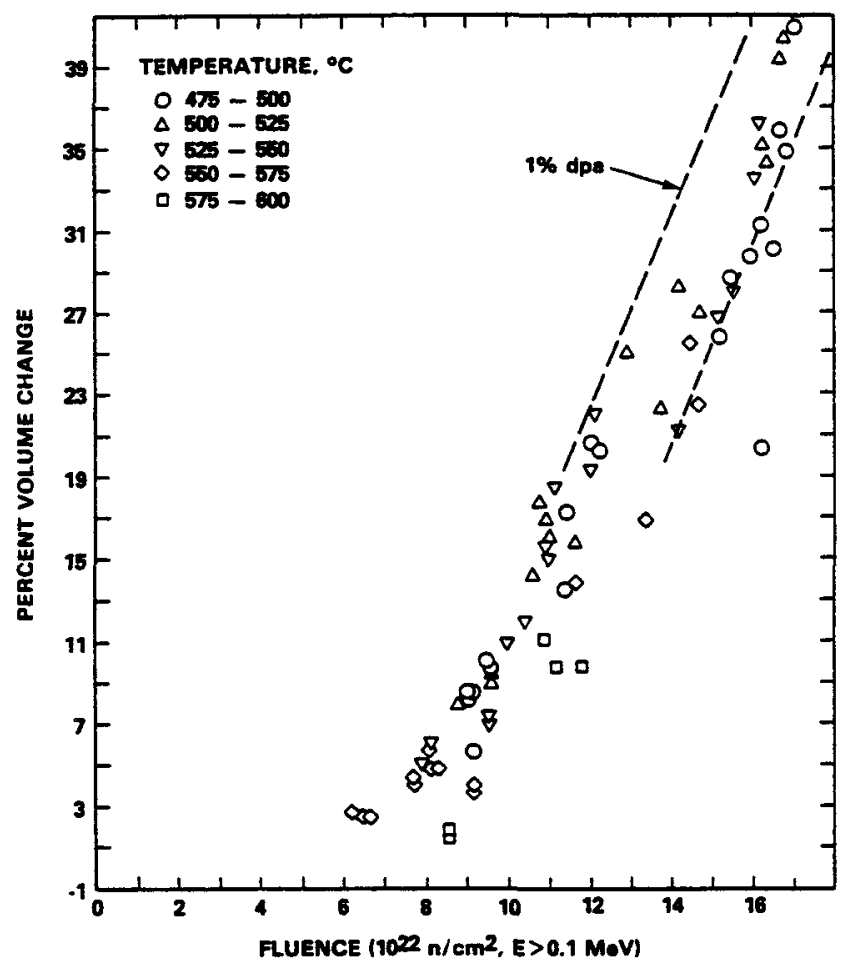

FIGURE 2. Swelling of $20 \%$ cold-worked AISI 316 fuel pin cladding. (20)

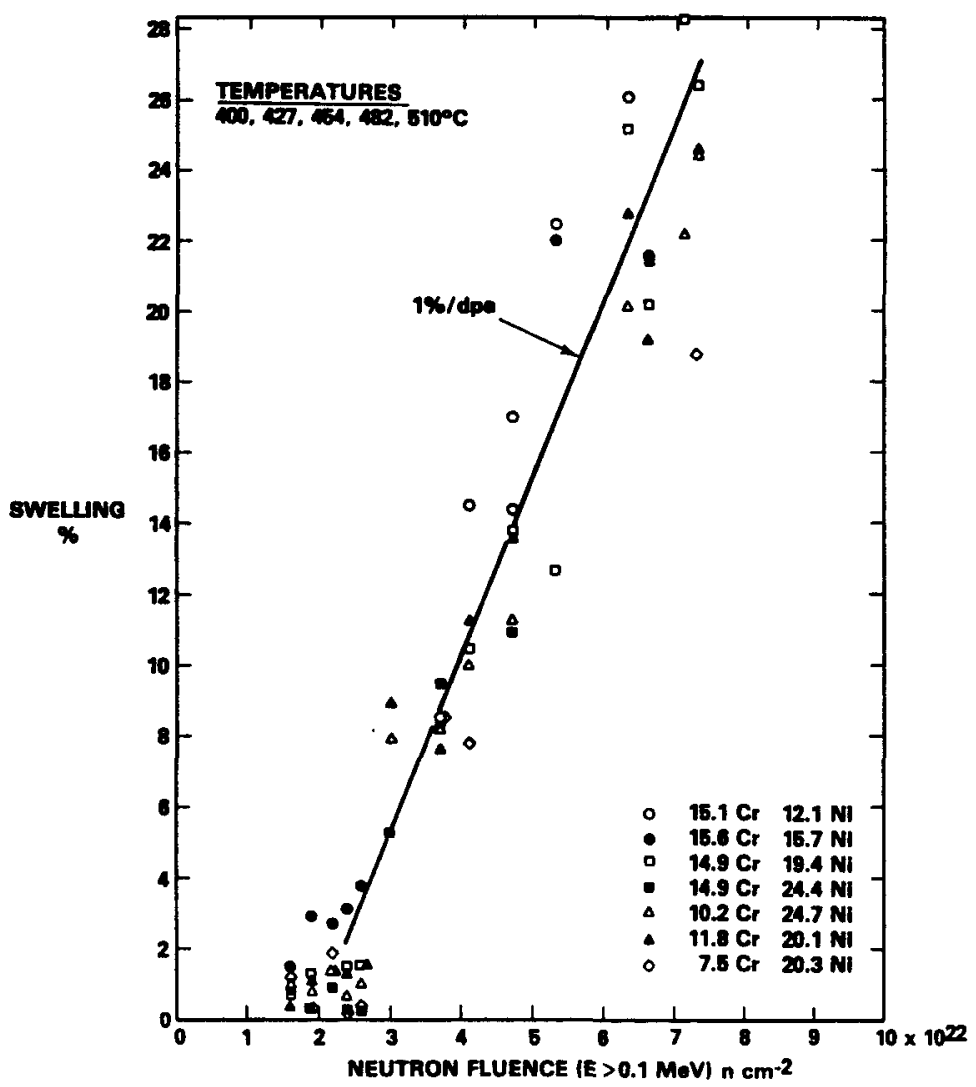

FIGURE 3. Swelling of seven $\mathrm{Fe}-\mathrm{Cr}-\mathrm{Ni}$ alloys in EBR-II at five temperatures in the range $400-510^{\circ} \mathrm{C} .(16)$ 


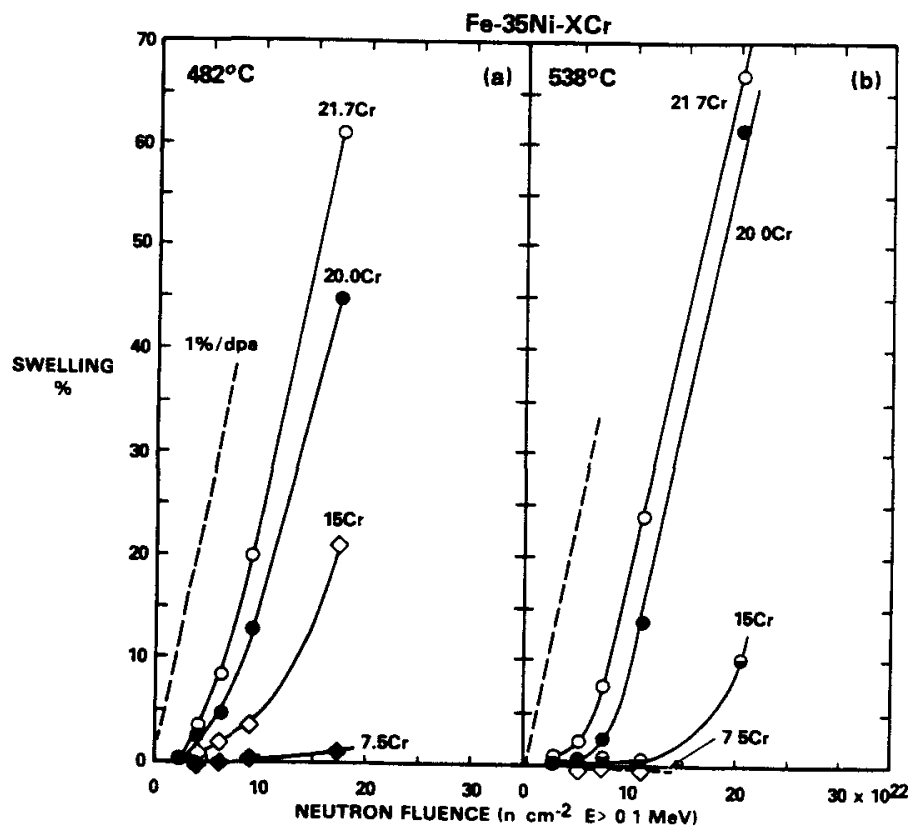

FIGURE 4. Influence of chromium level and temperature on the swelling of Fe-35Ni-XCr alloys in EBR-II. (16)

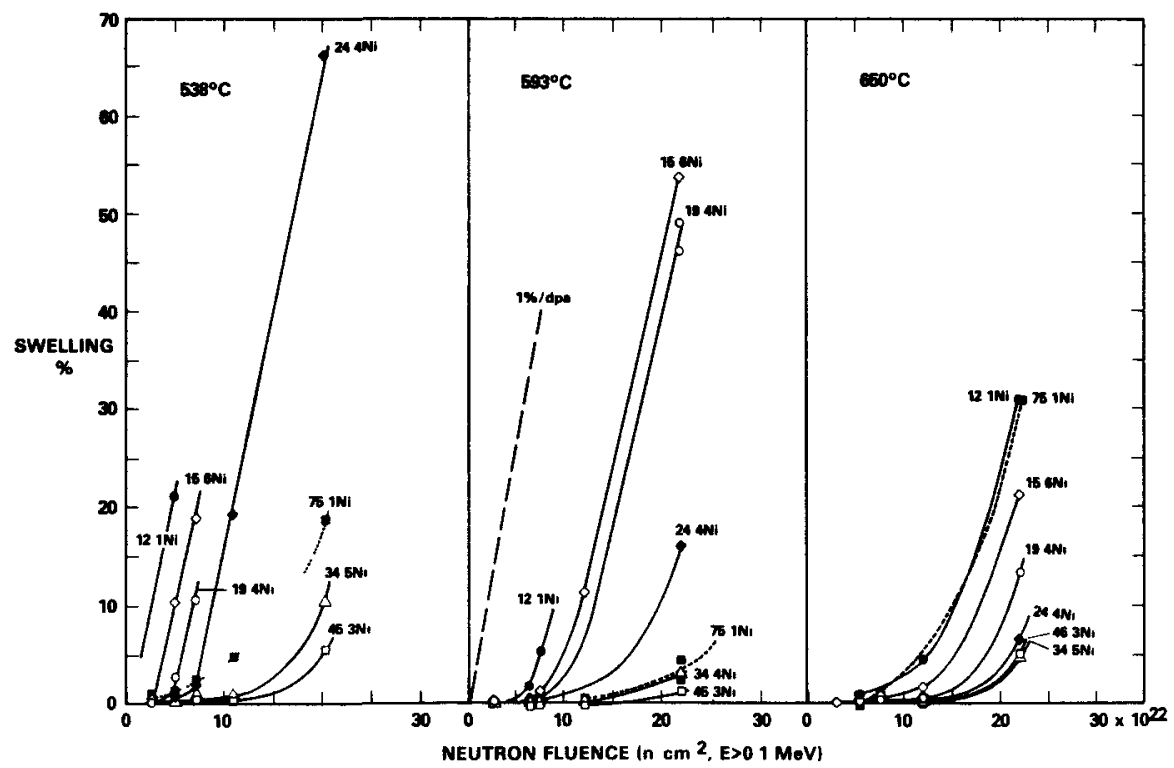

FIGURE 5. Influence of nickel level and temperature on the swelling of Fe-15Cr-XNi alloys in EBR-II. (16) 


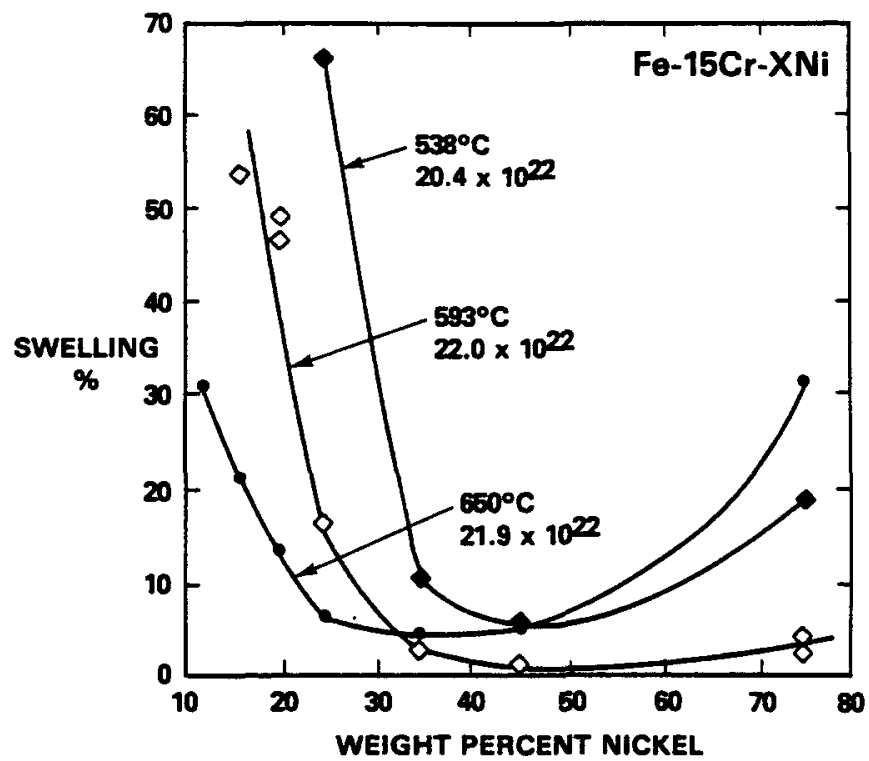

FIGURE 6. Dependence of swelling of $\mathrm{Fe}-15 \mathrm{Cr}-\mathrm{XNi}$ alloys on temperature, neutron fluence and nickel content. (16)

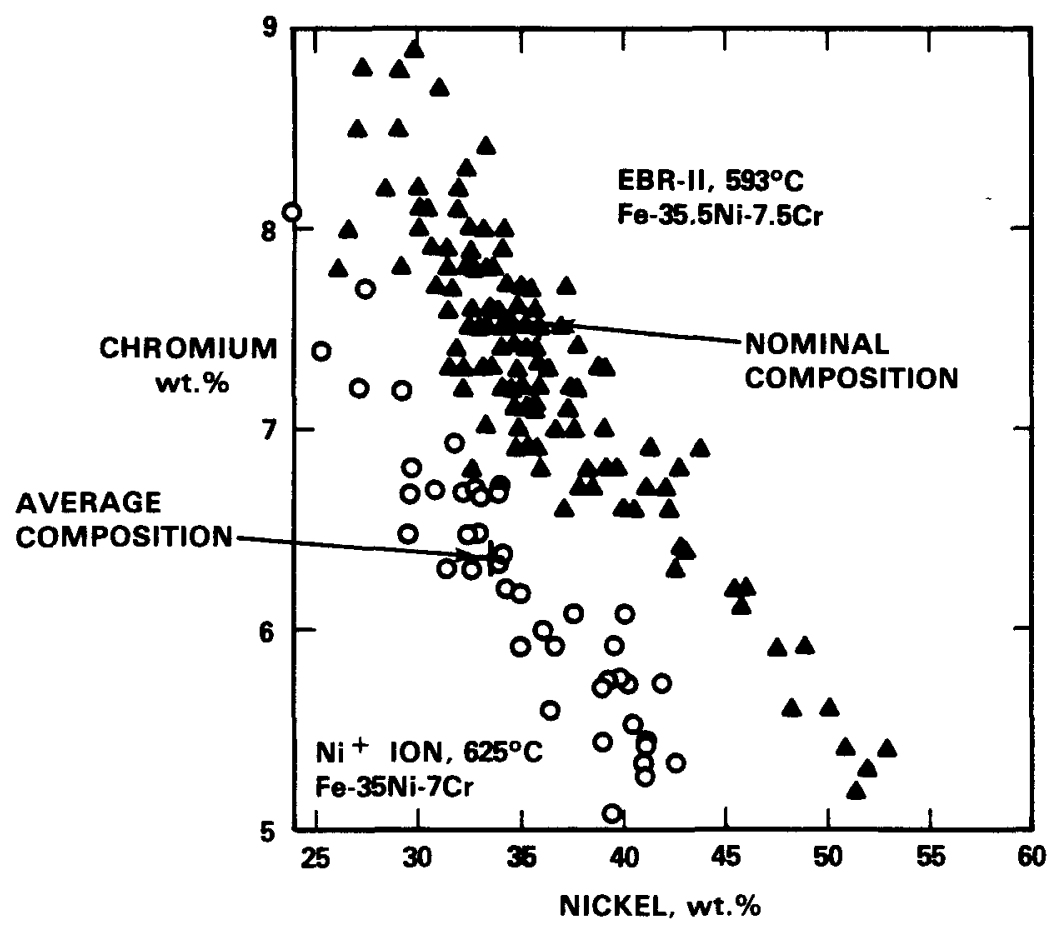

FIGURE 7. Local measurements of spinodal decomposition of Fe-Cr-Ni Invar alloys, illustrated by the tendency of nickel to separate from chromium and iron during irradiation by ions or neutrons. (26) 


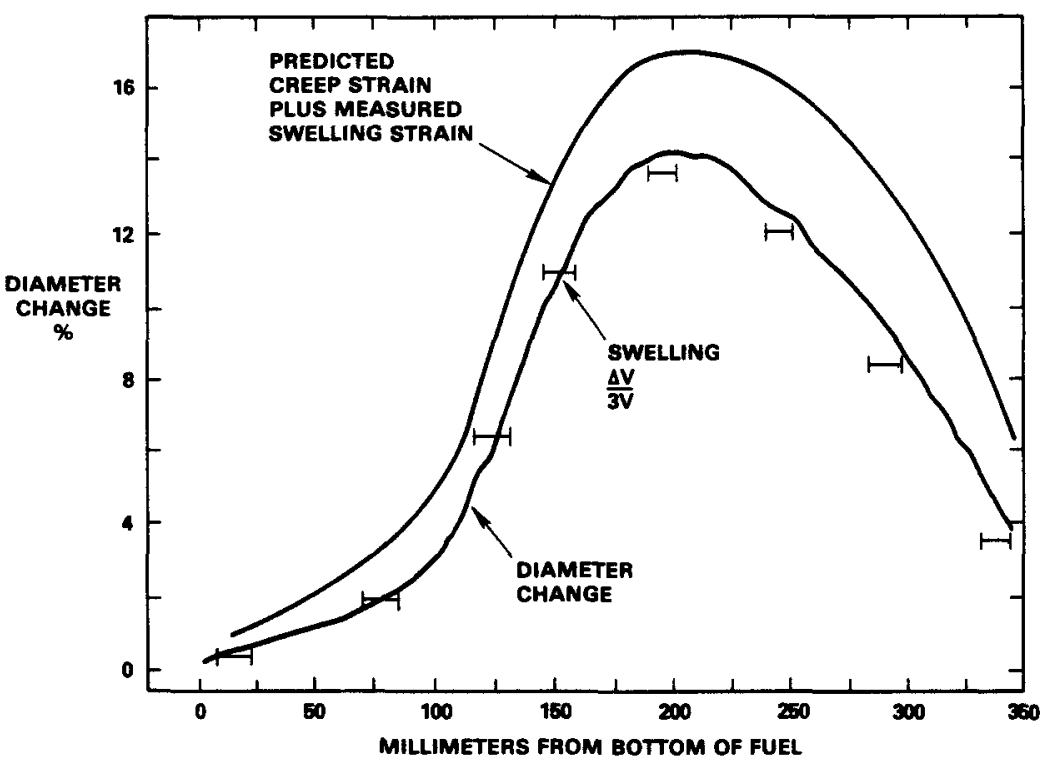

FIGURE 8. Comparison of predicted and measured diametral strains of $20 \%$ cold-worked AISI 316 cladding on a fuel pin irradiated to a peak fluence of $1.7 \times 10^{23} \mathrm{n} / \mathrm{cm}^{2}(\mathrm{E}>0.1 \mathrm{MeV})(20)$. Note that the measured diameter change appears to arise primarily from the swelling-reiated strain.

ure modes. As shown in Figure 8 Makenas has recently found that large underpredictions of creep strain occur in fuel pins with significant levels of swelling. The results of on-going analyses of pressurized creep tubes irradiated in EBR-II show that creep strains appear to saturate coincident with 7-10\% swe $1-$ ling. One consequence of this is that diameter changes at high fluence do not exceed $0.33 \% / d p a$ for any stress level. This strain rate therefore represents only post-transient swelling-induced deformation.

If large levels of void swelling tend to interfere with irradiation creep it might be expected that other deformation modes may also be affected. It has recently been found that the fracture modes in AISI 316 and titanium-modified AISI 316 undergo significant changes as swelling increases. There is a complete change in fracture mode from ductile to channel facture when swelling levels exceed $10 \%$ and when tensile tests are conducted at the irradiation temperature. As shown in Figure 9 a moderate amount of ductility remains and the fracture surfaces show significant ductility as evidenced by deformation of the sheared voids. When the tests are conducted at room temperature, however, there is a quasi-cleavage failure that occurs normal to the direction of applied stress and which shows the river patterns typical of cleavage fracture (Figure 10). The voids on the quasi-cleavage surface do not exhibit deformation. Although Huang $(29)$ as well as Hamilton and coworkers $(30)$ conclude that the fracture toughness of irradiated AISI 316 is sufficient for breeder and fusion applications, it appears that the tearing modulus at low temperatures is greatly reduced when significant swelling has occurred.

\subsection{Conclusions}

Based on the new insights discussed in this paper it appears that there are radiation-induced phenomena yet to be discovered. It is felt that most of these phenomena represent the response of the material to displacement damage and that neutron spectral considerations such a helium can be treated as second-order perturbations. Fast reactors will therefore continue to be a valuable tool for fusion materials studies. 


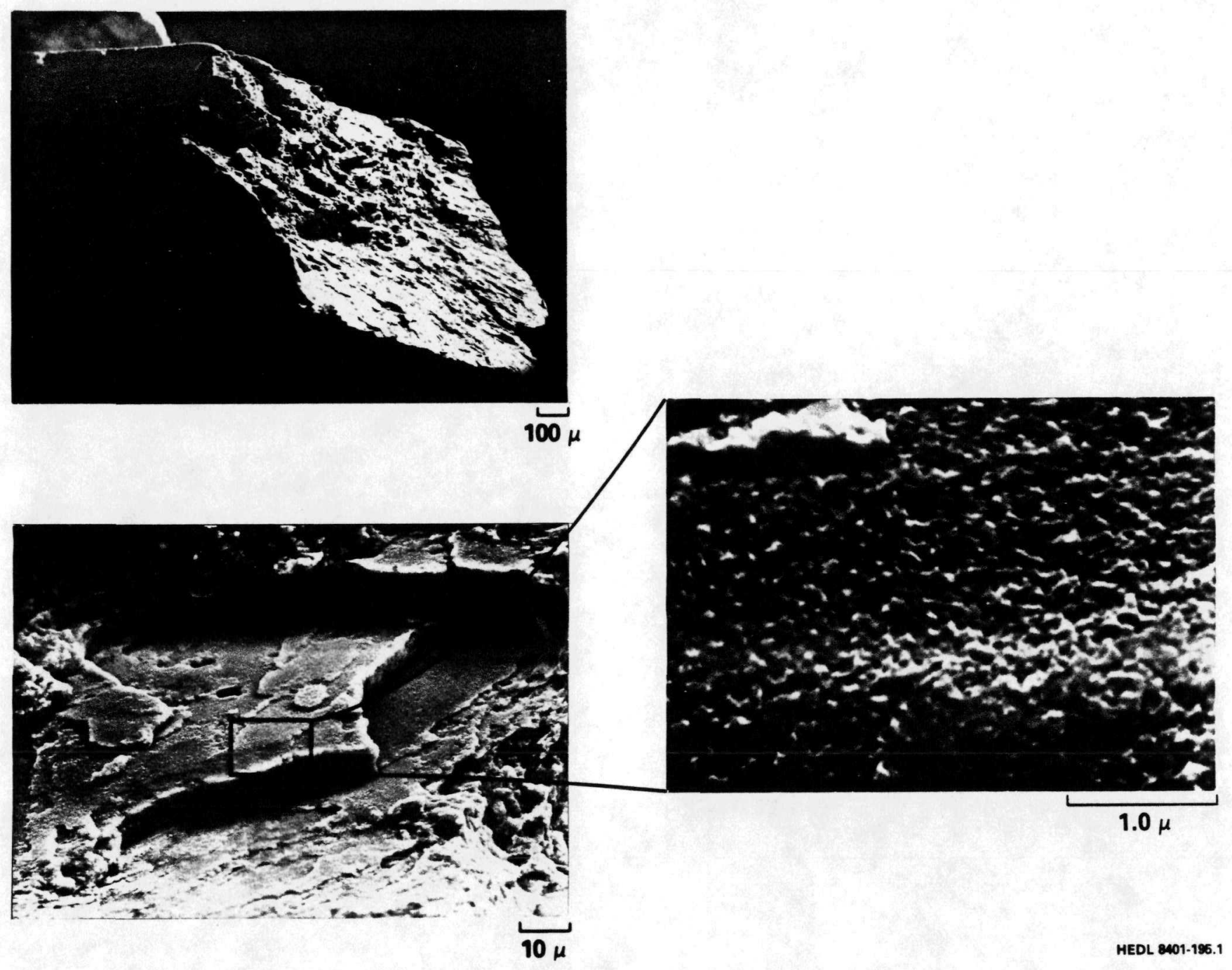

FIGURE 9. Channel fracture of $20 \%$ cold-worked AISI 316 duct irradiated at $460^{\circ} \mathrm{C}$ and tested at the same temperature. (Courtesy of M. L. Hamilton of HEDL) This material was irradiated to $15.5 \times 10^{22} \mathrm{n} / \mathrm{cm}^{2}(\mathrm{E}>0.1 \mathrm{MeV})$ and accumulated $7.2 \%$ strain before failure occurred.

\subsection{References}

1. D. G. Doran, J. Nucl. Mater. 117 (1983) 1.

2. F. A. Garner, J. Nuc1. Mater. 122 and 123 (1984) 459.

3. H. R. Brager and F. A. Garner, J. Nucl. Mater. 117 (1983) 159.

4. A. F. Rowcliffe and M. L. Grossbeck, J. Nucl. Mater. 122 and 123 (1984) 181.

5. W. J. S. Yang and M. L. Hamilton, J. Nucl. Mater. 122 and 123 (1984) 748.

6. S. Vaidyanathan, W. C. Bell and T. Lauritzen, Effects of Radiation on Materials: Eleventh Conf., ASTM STP 782, Eds., H. R. Brager and J. S. Perrin (American Society for Testing and Materials, 1982) p. 619. 


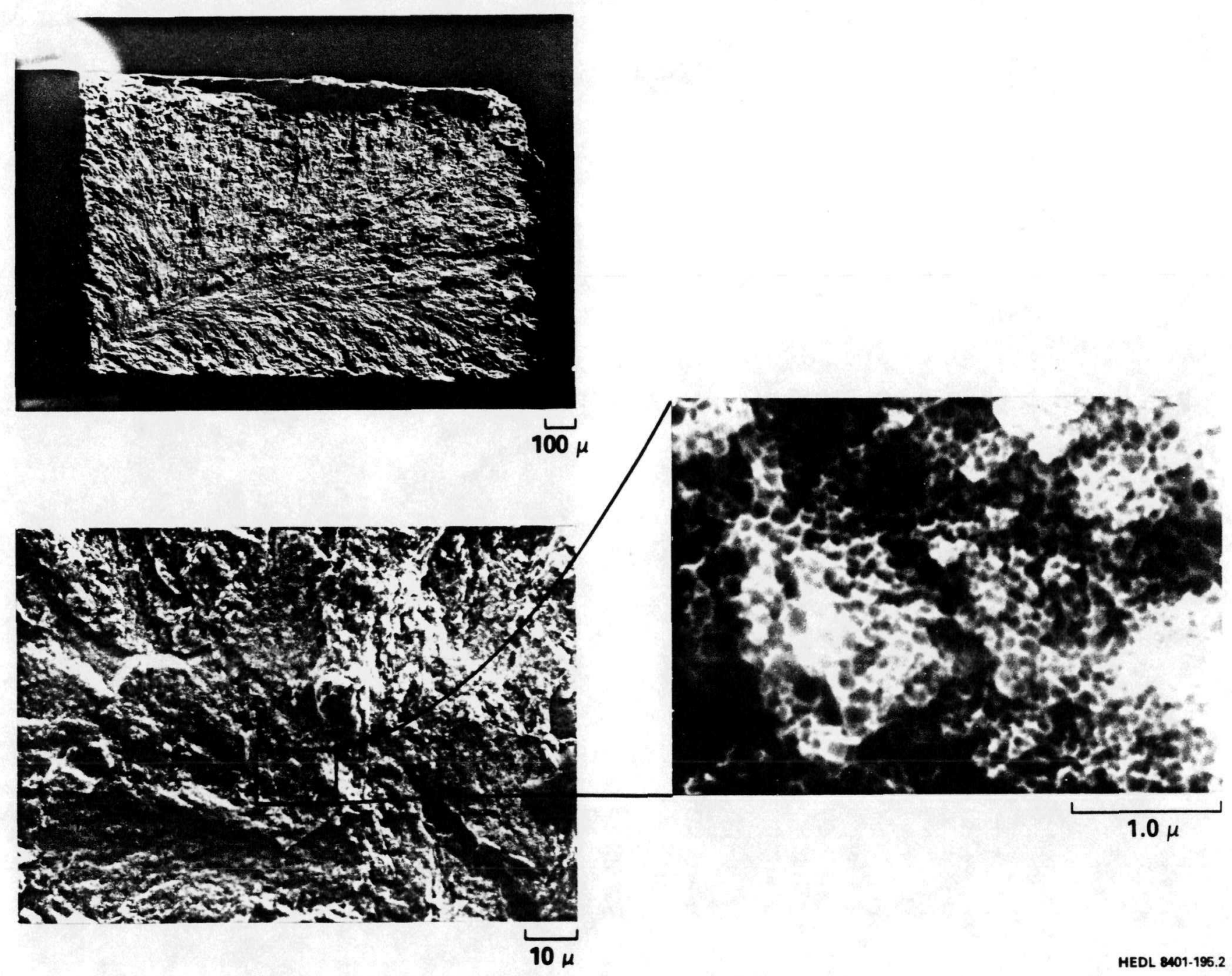

FIGURE 10. Quasi-cleavage fracture of $20 \%$ cold-worked AISI 316 duct irradiated to $15.5 \mathrm{n} / \mathrm{cm}^{2}$ (E $>0.1 \mathrm{MeV}$ ) at $460^{\circ} \mathrm{C}$ and tested at $20^{\circ} \mathrm{C}$. (Courtesy of M. L. Hamilton of HEDL). This material failed after $1.9 \%$ strain had occurred.

7. W. J. S. Yang, D. S. Gelles, J. L. Straalsund and R. Bajaj, "Post-irradiation Ductility Loss of Iron-Nickel Base Precipitation Hardenable Alloys," to be published in J. Nucl. Mater.

8. D. N. Brasky and D. W. Ramey, "A Modified Tritium Trick Technique for Doping Vanadium Alloys With Helium," to be published in Effects of Radiation on Materials: Twelfth Conf., ASTM STP 870, Eds., F. A. Garner and J. S. Perrin (American Society for Testing and Materials, 1985) in press.

9. H. R. Brager, F. A. Garner and P. J. Maziasz, DAFS Quarterly Progress Report D0E/ER-0046/19 (November 1984) 49.

10. R. L. Simons, DAFS Quarterly Progress Report DOE/ER-0046/12 (February 1983) 37.

11. R. J. Puigh and R. E. Schenter, "The In-Reactor Creep Rupture Experiment in MOTA, "to be published in Effects of Radiation on Materials: Twelfth Conf., ASTM STP 870, Eds., F. A. Garner and J. S. Perrin (American Society for Testing and Materials, 1985) in press. 
12. D. L. Smith et al., Blanket Comparison and Selection Study Final Report ANL/FPP-84-1, September 1984.

13. F. A. Garner and W. G. Wolfer, J. Nucl. Mater. 122 and 123 (1984) 201.

14. W. G. Wolfer, ibid., 367 .

15. F. A. Garner, J. Nuc1. Mater. 117 (1983) 177.

16. F. A. Garner and H. R. Brager, "Swelling of Austenitic Fe-Cr-Ni Ternary Alloys During Fast Neutron Irradiation," to be published in Effects of Radiation on Materials: Twelfth Conf., ASTM STP 870, Eds., F. A. Garner and 3. S. Perrin (American Society for Testing and Materials, 1985) in press.

17. H. R. Brager, F. A. Garner, D. S. Gelles and M. L. Hamilton "Development of Reduced Activation alloys for Fusion Service," HEDL-SA-3181, to be published in J. Nucl. Mater.

18. D. S. Gelles and F. A. Garner, "Swelling Behavior of Manganese-Bearing AISI 216 Steel," HEDL-SA-3150, to be published in J. Nucl. Mater.

19. V. A. Krasnoselov, V. I. Prokhorov, A. N. Kolesnikov and Z. A. Ostrovskii, Atomnaya Energiya, 54, No. $2(1983), 111$.

2.0 B. J. Makenas, "Swelling of 316 SS 20\% Cold Worked Fuel Pin Cladding and Ducts," to be published in Effects of Radiation on Materials: Twelfth Conf., ASTM STP 870, Eds., F. A. Garner and J. S. Perrin (American Society for Testing and Materials, 1985) in press.

21. F. A. Garner and H. R. Brager, "The Role of Phosphorus in the Swelling and Creep of Austenitic Alloys," HEDL-SA-3153, to be published in J. Nucl. Mater.

22. F. A. Garner, H. R. Brager and R. J. Puigh, "Swelling Behavior of Titanium-Modified AISI 316 Alloys," HEDL-SA-3149, to be published in J. Nuc T. Mater.

23. D. L. Porter and F. A. Garner, "Swelling of AISI $340 \mathrm{~L}$ in Response to Simultaneous Variations in Stress and Displacement Rates," to be published in Effects of Radiation on Materials: Twelfth Conf., ASTM STP 870, Eds., F. A. Garner and J. S. Perrin (American Society for Testing and Materials, 1985) in press.

24. F. A. Garner, "A Model Describing the Compositional Dependence of Void Nucleation in Irradiated $\mathrm{Fe}-\mathrm{Ni}-\mathrm{Cr}$ Alloys," HEDL-SA-3024 (1984) to be submitted to J. Nucl. Mater.

25. H. R. Brager and F. A. Garner, "Microsegregation Observed in Fe-35.5Ni-7.5Cr Irradiated in EBR-II," to be published in Effects of Radiation on Materials: Twelfth Conf., ASTM STP 870, Eds., F. A. Garner and J. S. Perrin (American Society for Testing and Materials, 1985) in press.

26. H. R. Brager, F. A. Garner and T. Lauritzen, DAFS Quarterly Progress Report DOE/ER-0046/19 (November 1984) 56.

27. H. R. Brager, F. A. Garner and M. L. Hamilton, "The Influence of Composition on the Microstructural Evolution and Mechanical Properties of Irradiated $\mathrm{Fe}-\mathrm{Cr}-\mathrm{Ni}$ Ternaries, " this volume.

28. W. G. Wolfer and F. A. Garner, DAFS Quarterly Progress Report DOE/ER-0046/17 (May 1984 ) 58.

29. F. H. Huang, Inter. J. of Fracture, 25 (1984) 181.

30. M. L. Hamilton, F. A. Garner and W. J. S. Yang, DAFS Quarterly Progress Report D0E/ER-0046/20, (Feb. 1985) 33.

\subsection{Future Work}

The reassessment of the utility of fast and thermal reactor data to fusion-relevant studies will continue as additional data become available.

\subsection{Publications}

This report will be published in a slightly shorter version in the $J$. of Nuclear Materials, Proceedings of the First International Conference on Fusion Reactor Materials, Tokyo, Japan, Dec. 3-6, 1984. 